\title{
UMA ANÁLISE DA FORMAÇÃO ARTÍSTICA DOS CONCRETISTAS PAULISTAS PELO MÉTODO DA BIOGRAFIA COLETIVA ${ }^{1}$
}

\author{
https://doi.org/10.33871/23580437.2021.8.1.138-152
}

Luis F. S. Sandes ${ }^{23}$

\begin{abstract}
Resumo: O concretismo paulista foi movimento de vanguarda atuante na década de 1950. O objetivo deste artigo é apresentar e analisar a formação artística dos artistas visuais e poetas concretistas. Essa formação pode ser dividida em dois polos. O polo mais formal envolveu escolas de arte, ateliês de professores artistas e escolas profissionalizantes. Já o polo menos formal reuniu novos locais de socialização, como museus de arte, a Seção de Arte da Biblioteca Municipal e bares, todos na cidade de São Paulo. O argumento é de que a formação artística não formal prevaleceu para os artistas concretistas em decorrência da não adequação das instituições de formação formal de meados do século XX para o florescimento e amadurecimento das ideias e práticas concretistas. $\mathrm{O}$ método utilizado foi o da biografia coletiva, segundo o proposto por Christophe Charle. Os materiais foram monografias sobre artistas, trabalhos acadêmicos, artigos de jornais, manifesto e livros de historiografia da arte e sociologia. As considerações finais discutem a importância dos espaços não formais de formação artística para o movimento concretista.
\end{abstract}

Palavras-chave: formação artística; concretismo; São Paulo; arte moderna; método da biografia coletiva.

\section{AN ANALYSIS OF THE ARTISTIC FORMATION OF THE CONCRETE ARTISTS IN SAO PAULO BY THE COLLECTIVE BIOGRAPHY METHOD}

\begin{abstract}
During the 1950s, there was an avant-garde movement in Sao Paulo of concrete art. The goal of this paper is to present and analyse the artistic formation of concrete visual artists and poets. This is divided into two poles. The more formal gathered art schools, ateliers, and professional schools. The less formal gathered new sites of socialization, as the art museums, a room at a local public library, and bars, all in Sao Paulo city. The argument is that the non-formal artistic formation has prevailed for the concrete artists due to the non-adequacy of the formal teaching institutions of mid- $20^{\text {th }}$ century for the flourishing and maturation of the concretist ideas and practices. The method was taken from the approaches of Christophe Charle to the collective biography method. Materials used were monographs on artists, academic papers, newspapers' articles, a manifesto and books on art historiography and sociology. The final remarks discuss the importance of the non-formal artistic formation sites for the avant-garde movement.
\end{abstract}

Keywords: artistic formation; concrete art; Sao Paulo; modern art; collective biography method.

\footnotetext{
${ }^{1}$ Este artigo é decorrente da dissertação de mestrado defendida pelo autor junto ao Programa de Pós-Graduação em Ciências Sociais da Pontifícia Universidade Católica de São Paulo (PUC-SP) em 2018, cujo título é "Geração concretista paulista: uma biografia coletiva". A orientação foi do prof. dr. Guilherme Simões Gomes Júnior. O problema da pesquisa se referiu à constituição do grupo concretista e à sua atuação na modernização do campo artístico brasileiro. A dissertação fez parte de projeto coordenado pelo orientador intitulado "Gerações e grupos na arte brasileira no século XX: a Família Artística Paulista, o Concretismo e a Geração de 1980".

${ }^{2}$ Doutorando junto ao Programa de Pós-Graduação em Arquitetura e Urbanismo da Universidade de São Paulo (USP), sob orientação do prof. dr. Agnaldo Farias. Pesquisa a relação de artistas contemporâneos brasileiros com a abstração geométrica. Pesquisou o concretismo paulista, uma vanguarda moderna da abstração geométrica, durante seu mestrado, tendo obtido como resultado, além da dissertação, diversas publicações acadêmicas (incluindo entrevistas com colecionador e artistas). Suas publicações encontram-se reunidas em: https://usp-br.academia.edu/LuisFSSandes. Orcid: http://orcid.org/0000-0003-17621412. E-mail: luis.sandes@usp.br

${ }^{3}$ Agradeço à Juliana Miraldi, que, com leitura atenciosa, questionamentos instigantes e sugestões pertinentes, generosamente colaborou para que este artigo fosse aprimorado significativamente.
} 


\section{UN ANÁLISIS DE LA FORMACIÓN ARTÍSTICA DE LOS CONCRETISTAS DE SÃO PAULO MEDIANTE EL MÉTODO DE LA BIOGRAFÍA COLECTIVA}

Resumen: La vanguardia del arte concreta fue actuante en San Pablo en los años 1950. El objetivo en este artículo es presentar y analizar la formación artística de los artistas visuales y poetas concretos. Esa formación puede ser dividida en dos polos. El más formal reunió escuelas de artes, talleres y escuelas profesionales. El menos formal reunió nuevos sitios de socialización, como museos de arte, una sala en una biblioteca municipal y bares, todos en la ciudad de San Pablo. El argumento es que la formación artística no formal prevaleció para los artistas concretos debido a la no adecuación de las instituciones de aprendizaje formales de mediados del siglo XX para lo florecimiento y maduración de las ideas e practicas concretas. El método que fue empleado es lo método de la biografía colectiva, según Christophe Charle. Los materiales fueron monografías sobre artistas, trabajos académicos y libros de historiografía y sociología. Las últimas observaciones debaten la importancia de los sitios no formales de formación artística para el movimiento concreto.

Palabras Clave: formación artística; arte concreta; San Pablo; arte moderno; método de la biografía colectiva.

\section{Introdução}

O concretismo em São Paulo, enquanto grupo, surgiu a público em 1952 e teve seu auge na Bienal de São Paulo de 1955, tendo obtido uma posição central no meio artístico naquela década. Os artistas dessa vanguarda almejavam uma ruptura com "o velho", "o naturalismo" e "o não figurativismo hedonista", conforme expuseram no Manifesto Ruptura, divulgado quando da exposição inaugural em $1952^{4}$. Os concretistas exploravam novos materiais, métodos, formas, tintas e suportes. Além disso, propunham uma arte abstrata geométrica que ocupasse o lugar deixado pela ruptura pretendida com a arte representativa de então. Esses artistas, tanto poetas como artistas visuais, tiveram uma formação artística única, ainda pouco estudada.

Neste artigo, o objetivo é apresentar e analisar a formação artística desse grupo de artistas ${ }^{5}$. Essa formação foi variada e se deu principalmente entre as décadas de 1930 e 1950. Envolveu, no polo mais formal, frequência de escolas de arte, ateliês de professores artistas e escolas profissionalizantes. Já no polo menos formal tiveram destacada importância novos locais de socialização, como, por exemplo, a Seção de Arte da Biblioteca Municipal de São Paulo e a boêmia - os artistas frequentavam certos bares e restaurantes, onde discutiam vivamente arte. Nesse mesmo polo, podem ser indicados o Museu de Arte Moderna de São Paulo (MAM-SP), o Museu de Arte de São Paulo (Masp) e a Bienal de São Paulo, que, surgida em 1951, também teve peso na formação dos concretistas.

Para atingir o objetivo do artigo, foram analisados diversos tipos de materiais, entre os quais estão monografias sobre artistas, trabalhos acadêmicos, artigos de jornais de época, manifesto e livros de historiografia da arte e de sociologia.

Trata-se de grupo composto por quinze artistas. São eles: Alexandre Wollner, Anatol Wladyslaw, Antônio Maluf, Augusto de Campos, Décio Pignatari, Lothar Charoux, Kazmer Féjer, Judith Lauand, Hermelindo Fiaminghi, Haroldo de Campos, Geraldo de Barros, Leopold Haar, Luiz Sacilotto, Maurício Nogueira Lima e Waldemar Cordeiro. Estão arrolados os três membros fundadores da revista-livro Noigandres, os onze membros do Ruptura

\footnotetext{
${ }^{4}$ A única reprodução completa do Manifesto Ruptura existente é a do exemplar da Coleção Adolpho Leirner do Museu de Belas Artes de Houston (EUA) e está disponível online em: <https://emuseum.mfah.org/objects/60078/manifestoruptura?ctx $=45 \mathrm{~d} 3 \mathrm{ba} 898 \mathrm{abb} 7 \mathrm{da} 7 \mathrm{f} 4883 \mathrm{cec} 26 \mathrm{~d} 811 \mathrm{~d} 1686150 \mathrm{~cd} \& \mathrm{idx}=1>$.

${ }^{5}$ Cabe destacar, de modo sucinto, a diferença da formação dos concretistas com a de outros grupos de artistas brasileiros em outros períodos históricos. Atualmente, na arte contemporânea brasileira, por exemplo, o modelo de formação de artista que prevalece é o das escolas de artes de nível superior, acompanhado das residências artísticas, seja no Brasil, seja no exterior. Mesmo se a comparação for feita com artistas do século XX, o contraste é evidente. Tomem-se, como exemplo, os modernistas de 1922, para os quais viagens de estudos à Europa, com destaque para a França, preponderavam como os elementos de formação artística mais importantes. Para os modernistas que participaram da I Exposição Geral de Belas Artes, em 1922, prevaleciam os estudos no Liceu de Artes e Ofícios, em São Paulo, e na Escola de Belas Artes, na então capital federal.
} 
ao passar dos anos e um artista não filiado ao grupo central do concretismo paulista, mas que dele esteve muito próximo: Maluf.

Esses artistas foram escolhidos por terem residido na cidade de São Paulo no período estudado (de 1952 a 1959, a saber, o de atividade mais coesa do movimento) e por terem relações sociais orgânicas entre si. Isto é, participaram do mesmo grupo concreto no sentido de Mannheim (Ruptura), participaram conjuntamente de exposições de arte, subscreveram conjuntamente o Manifesto, frequentaram-se como colegas ou como amigos, entre outros indicadores de proximidade. Além desses fatores, teve peso terem os artistas compartilhado um mesmo projeto estético, a despeito das diferenças individuais existentes ${ }^{6}$.

Argumenta-se que a formação artística não formal prevaleceu para os artistas concretistas em decorrência da não adequação das instituições de formação formal de meados do século XX para o florescimento e amadurecimento das ideias e práticas concretistas. Por um lado, as instituições mais tradicionais de então não costumavam arregimentar a maior parcela dos indivíduos das classes sociais das quais eles faziam parte - e, se esses indivíduos porventura fossem incorporados, acabariam possivelmente se conformando e abrindo mão das inovações modernistas de que estavam imbuídos. Houve, contudo, entre os concretistas, quatro pessoas que tiveram formação em academias de belas artes - nesses casos, o desenvolvimento do abstracionismo geométrico por parte desses artistas correu apesar da formação acadêmica. Por outro lado, às instituições de formação formal que os concretos frequentaram não era possível, com certas exceções, prover uma formação atualizada e moderna que colaborasse diretamente para a produção de ideias e obras desses que eram ou se tornariam concretistas. Assim, essas dificuldades no campo formal da formação em artes acabaram por deslocar a formação dos concretos para um campo menos formal, como se busca demonstrar ao longo do artigo.

Em suma, a formação artística formal estava ou fora do alcance dos concretistas ou não favorecia a poética vanguardista; assim, teve destacada importância o recurso desses artistas aos espaços informais, nos quais socializaram entre si e desenvolveram suas novas ideias e práticas.

O método empregado foi o da biografia coletiva, ou método prosopográfico, de acordo com as proposições teóricas de Charle. Ademais, foram utilizados conceitos sociológicos: "campo" de Bourdieu (1996; 2010) e "geração" e noções correlatas (por exemplo, unidade de geração e grupo concreto) de Mannheim ([1986]). Os materiais pesquisados foram biografias, manifesto, catálogos de exposições, estudos monográficos sobre artistas, entrevistas ao autor e matérias e críticas de arte publicadas em jornais.

Convém apresentar brevemente os referenciais teóricos utilizados. O método da biografia coletiva se caracteriza por ser um modo de lidar com materiais históricos e de fazer sociologia no passado. Com esse método, que é flexível, determina-se a população pesquisada, à qual se elabora "um questionário biográfico cujos diferentes critérios e variáveis servirão à descrição de sua dinâmica social, privada, pública, ou mesmo cultural, ideológica ou política" (CHARLE, 2006, p.41). A biografia coletiva resultante permite "melhor compreender as clivagens internas dos diferentes grupos estudados e suas dinâmicas sociais e geracionais, ou ainda as redes sociais dominantes" (CHARLE, 2006, p.48). Ademais, o método se opõe à "velha história das elites [...][,] fixada em personagens e atos excepcionais" (HEINZ, 2006, p.10).

Escolheu-se pelo método da biografia coletiva, pois ele seria o "enfoque metodológico preferencial" para o estudo das elites, sendo este um termo instrumental relativo a grupos sociais "no topo"; seu objetivo é a compreensão das relações internas ao grupo e das com os demais setores sociais (HEINZ, 2006, p.7-8). O grupo concretista é entendido como elite uma vez que se tratava de uma vanguarda artística.

Para Bourdieu (1996; 2010), campo trata-se de espaço social relativamente autônomo a outras esferas sociais que estabelece suas próprias normas de operação e que gira em torno de uma aposta que lhe diz respeito. No campo artístico, aqui estudado, essa aposta é a legitimidade.

Mannheim faz revisão das abordagens de sua época sobre o problema das gerações e, para ele, o problema das gerações "é um dos guias indispensáveis para uma compreensão da estrutura dos movimentos sociais e intelectuais" (MANNHEIM, [1986], p.129). Também, o autor desagrega geração em quatro noções, listadas em crescente nível de abstração: grupo concreto, unidade de geração, geração real e localização de geração.

${ }^{6}$ Nesse sentido, para Morais (2014 [1977], p.294), “[...] É possível que o Concretismo, como movimento, desapareça na individualidade de cada um dos seus participantes. [...]"

R. Inter. Interdisc. Art\&Sensorium, Curitiba, v.8, n.1, p. 138 - 152 Jan.- Jun. 2021 
Para Mannheim ([1986, p.132-133), grupo concreto designa “[...] a união de vários indivíduos através de laços naturalmente desenvolvidos ou conscientemente desejados". Pode tanto ser de ordem "natural" (por exemplo, a família ou a tribo) ou racional (associações de todo tipo, inclusive as artísticas). O grupo Ruptura pode ser entendido como um caso de grupo concreto, dado que seus membros se conheciam um a um, além de terem em comum certos objetivos e características.

Em um nível maior de abstração, as unidades de geração se caracterizam por polarização e antagonismo, além de diferentes formas de trabalho da experiência vivida. Dois exemplos de unidade de geração relacionados ao momento histórico estudado podem ser apontados. Uma seria das abstrações, ou seja, de suas diversas correntes: artistas abstrato-geométricos, tendências geometrizantes e abstração informal, ou lírica. Outra diria respeito aos artistas figurativistas.

A geração real se ancora na partilha de um mesmo processo histórico-social pelos indivíduos, que, desse modo, experimentam os mesmos fatos e acontecimentos. Englobaria, por exemplo, indivíduos que nascidos em anos próximos, participam de realidades sociais próximas.

A localização de geração se refere a um critério temporal, ou seja, uma geração é aquela que se compõe em um dado tempo. Baseia-se em fatores biológicos. Seriam, por exemplo, os indivíduos nascidos em certo ano.

As contribuições dos diferentes autores são complementares. Os aportes de Bourdieu complementam os de Mannheim na medida em que oferecem mais forma ao conceito de geração. Já os aportes de Charle têm sua relevância, pois trata-se de um estudo de uma elite (aqui, uma vanguarda artística); assim sendo, uma biografia coletiva propicia a visualização de divisões dentro de um grupo social e de suas dinâmicas geracionais e sociais.

$\mathrm{O}$ texto está estruturado da seguinte forma. Primeiramente, apresentam-se o movimento vanguardista abordado e seu contexto à época. Após, explora-se e avalia-se a formação formal dos artistas concretos, que engloba escolas de arte, ateliês de artistas professores e escolas profissionalizantes. Em seguida, levanta-se e explica-se a formação não formal desses artistas, em recintos como a Seção de Arte da Biblioteca Municipal, o Masp, o MAM-SP e os redutos boêmios, além das bienais de arte. Por fim, apresentam-se as considerações finais, que discutem a importância dos espaços não formais de formação artística para o movimento concretista e a rarefação de instituições artísticas sólidas em meados do século passado, dando-se ênfase ao argumento do artigo. Também se discute a pertinência do uso do método da biografia coletiva e apresentam-se novas possibilidades de pesquisas para o futuro.

\section{Concretismo paulista e seu contexto}

O concretismo foi movimento de vanguarda que se insurgiu contra a figuração, então dominante. Grandes nomes dessa tendência eram, por exemplo, Di Cavalcanti (1897-1976) e Portinari (1903-1962). Os artistas figurativistas se valiam da figuração para retratar o Brasil "autenticamente", segundo Durand (2009, p.139), registrando a miséria, a cultura popular, os migrantes, a elite cultural, entre outros assuntos. Contrastando com isso, os concretistas buscavam uma arte que se valesse apenas de linhas, cores e formas geométricas, que não tivesse um significado fora da obra ou que não representasse algo existente no mundo ordinário. O mais destacado teórico e artista concretista foi Waldemar Cordeiro (1925-1973).

A aparição em público do movimento se deu com a exposição "Ruptura", ocorrida em dezembro de 1952 no MAM-SP, "após quatro anos de luta semiclandestina [...]", segundo Cordeiro (1953). Os sete membros iniciais, participantes dessa mostra e subscritos no ali divulgado Manifesto Ruptura, foram: Waldemar Cordeiro, Lothar Charoux (1912-1987), Geraldo de Barros (1923-1998), Luiz Sacilotto (1924-2003), Kazmer Féjer (1923-1989), Leopold Haar (1910-1954) e Anatol Wladyslaw (1913-2004). Nos anos posteriores, aderiram ao Ruptura: Judith Lauand (1922), Nogueira Lima (1930-1999), Alexandre Wollner (1928-2018) e Hermelindo Fiaminghi (19202004).

Lançada em novembro de 1952, a revista-livro Noigandres, de poesia experimental, enveredou pela poesia concreta apenas a partir do segundo número, que foi publicado em 1955. A essa altura, os poetas responsáveis pela publicação eram os irmãos Augusto de Campos (1931) e Haroldo de Campos (1929-2003) e Décio Pignatari (19272012), que ficaram conhecidos como "trio Noigandres". O contato desses poetas com os artistas visuais se deu após o lançamento da primeira edição.

A segunda edição de Noigandres saiu à luz em fevereiro de 1955. Contou apenas com textos dos irmãos Campos, dado que Pignatari estava em longa viagem à Europa, quando realizou contatos importantes para que a poesia concreta se desenvolvesse. Em Ulm, conheceu o poeta suíço-boliviano Eugen Gomringer (1925), que era secretário

R. Inter. Interdisc. Art\&Sensorium, Curitiba, v.8, n.1, p. 138 - 152 Jan.- Jun. 2021 
de Max Bill (1908-1994) na Escola de Ulm. (KHOURI, 2006, p.25). Nessa mesma cidade, Pignatari, que fez sua turnê europeia de 1954 a julho de 1956, também encontrou Tomás Maldonado (1922-2018), pintor e professor argentino ligado ao concretismo.

Com obras postas lado a lado, artistas visuais e poetas concretistas participaram da "I Exposição Nacional de Arte Concreta", que ocorreu no MAM-SP em 1956 e no Museu de Arte Moderna do Rio de Janeiro (MAM-Rio) em 1957 e que foi o "lançamento público" da poesia concreta brasileira, segundo Campos (2006, p.115). Integraram essa mostra vinte e cinco artistas - a maioria era de pintores e havia desenhistas e gravuristas, além de poetas. Ao passo que uniu concretistas paulistas e cariocas, essa exposição intensificou os processos de comparação, disputa e diferenciação entre ambos.

Ao longo de toda a década de 1950, a Bienal de São Paulo foi de elevada importância para o meio local e para os concretistas em especial, sobre o que se desenvolve na sequência. Teve sua primeira edição em 1951, junto das festividades do IV Centenário da cidade de São Paulo. Levando em conta suas edições iniciais, dessa até a quinta, Herkenhoff (2009, p.33) considerou que "a Bienal de São Paulo era um sol que resplandecia a cada dois anos e alimentou a arte brasileira por um longo período". Com a Bienal, artistas desvinculados do circuito aristocrático dessa cidade puderam almejar serem reconhecidos, uma vez que ela se tornou "[...] o lugar responsável pela aceitação desses artistas antes invisíveis" (ALAMBERT; CANHÊTE, 2004, p.24). Pedrosa (2000, p.288) escreveu que os artistas e entusiastas ao redor de Cordeiro "[...] foram os únicos que, ao abrir-se a I Bienal, já tinham um ponto de vista formado, e a receberam não como basbaques ou negativamente [...]", o que corrobora a ideia de "luta clandestina" prévia afirmada por esse artista, uma vez que esse ponto de vista indicado por Pedrosa deve ter sido constituído em reuniões desses artistas.

Sobre a origem social dos concretistas paulistas, cabe lembrar que a maioria deles era de classe média ou baixa, havendo diversos proletários entre eles. Amaral $(1998$, p.312) listou como profissões desses artistas com ligações à indústria nascente: "[...] químico industrial, desenhista técnico, publicitário, arquiteto, paisagista, artista gráfico, ilustrador, industrial têxtil, cartazista, fotógrafo, cromista, diagramador, vitrinistas, desenhista industrial". Além disso, houve dois professores: Lauand foi professora escolar e Charoux, de pintura. Os poetas também não foram ligados à indústria. Haroldo de Campos, graduado em Direito, fez carreira administrativa e jurídica na Universidade de São Paulo (USP) e também foi tradutor, ensaísta e professor universitário. Augusto de Campos, também graduado em Direito, foi procurador do estado de São Paulo, além de tradutor e ensaísta. Décio Pignatari, mais um graduado em Direito, teve certa ligação com a indústria, uma vez que foi publicitário. Ademais, atuou como ensaísta, tradutor, professor universitário e comunicador na imprensa.

Para Adolpho Leirner, "[...] os artistas procuravam sobreviver de outras formas", dado que "eles não poderiam viver com a arte deles [...]" (SANDES, 2017, p.315), porque não havia interesse mercadológico por suas produções artísticas. A despeito do reconhecimento artístico obtido por obras e artistas concretistas, o interesse comercial foi tardio, tendo surgido apenas a partir dos anos 1960, capitaneado por Leirner e levando décadas para se tornar mais vultuoso. Na década de 1950, período de atividade do concretismo enquanto movimento artístico, a circulação de obras se dava na forma de presentes trocados entre os artistas. Importa destacar que é na década que 1960 que surge um mercado de arte no Brasil, que operava tanto arte moderna como contemporânea, ainda que esta muito timidamente. Segundo Durand (2009, p.193), entre 1949 e 1963, “[...] se dá a consolidação e o declínio das galerias de arte acadêmica e emergem as lojas de arte moderna procurando localizar-se nos novos quarteirões do comércio de luxo".

Quanto aos locais de nascimento dos artistas, há bastante variedade. Cinco deles nasceram na capital do estado de São Paulo: Wollner, irmãos Campos, Fiaminghi e Maluf. Quatro deles, no interior desse estado: Geraldo, Sacilotto, Pignatari e Lauand. Cinco deles nasceram no exterior, ainda que um deles, Cordeiro, não tenha sido registrado como estrangeiro: Cordeiro, Wladyslaw, Féjer, Haar e Charoux. Um único nasceu em outro estado brasileiro: Nogueira Lima.

\section{Formação artística formal dos artistas concretos}

Neste momento, são apresentados e discutidos os principais espaços de formação artística formal frequentados pelos concretistas paulistas entre as décadas de 1930 e 1950 na cidade de São Paulo e em outras cidades do mundo, uma vez que vários deles tiveram sua iniciação artística em seus países natais. Trata-se de escolas de arte, ateliês de artistas professores e escolas profissionalizantes. Nomeadamente, discutem-se o Liceu de Artes e Ofícios, Instituto Profissional Masculino, a Escola Livre de Arte Plásticas, o ateliê de Samson Flexor, o Instituto de Arte 
Contemporânea do Masp, a alemã Escola de Ulm, a Escola de Belas Artes de Araraquara, academias de belas artes europeias e instituições de ensino superior fora do campo das artes, nessa ordem.

Os principais dados referentes a essas instituições são sinteticamente apresentados na tabela I, a seguir, com o objetivo de tornar mais visível o contexto das instituições de formação artística na São Paulo da época estudada. Em sua quarta coluna, indicam-se os artistas que já poderiam ser considerados concretos à época de sua participação/frequência na instituição ou que se tornaram concretos posteriormente.

\begin{tabular}{|c|c|c|c|c|c|}
\hline Instituição & $\begin{array}{r}\text { Ano de } \\
\text { fundação }\end{array}$ & $\begin{array}{r}\text { Ano de } \\
\text { encerra } \\
\text { mento }\end{array}$ & $\begin{array}{l}\text { Artistas concretos } \\
\text { que frequentaram }\end{array}$ & $\begin{array}{r}\text { Outros artistas que } \\
\text { frequentaram }\end{array}$ & Professores \\
\hline $\begin{array}{l}\text { Academia de } \\
\text { Belas Artes de } \\
\text { Cracóvia }\end{array}$ & 1818 & $\begin{array}{r}\mathrm{em} \\
\text { funciona } \\
\text { mento }\end{array}$ & Haar & $\begin{array}{r}\text { Leon Wyczółkowski, Stanisław } \\
\text { Wyspiański, Mariusz Zaruski, } \\
\text { Wilhelm Sasnal }\end{array}$ & \\
\hline $\begin{array}{l}\text { Academia de } \\
\text { Belas Artes de } \\
\text { Roma }\end{array}$ & 1870 & $\begin{array}{r}\text { em } \\
\text { funciona } \\
\text { mento }\end{array}$ & Cordeiro & & \\
\hline $\begin{array}{l}\text { Liceu de Artes } \\
\text { e Ofícios }\end{array}$ & 1873 & $\begin{array}{r}\mathrm{em} \\
\text { funciona } \\
\text { mento } \\
\text { (reformul } \\
\text { ado) }\end{array}$ & $\begin{array}{r}\text { Fiaminghi, } \\
\text { Charoux }\end{array}$ & $\begin{array}{r}\text { Benedito José de Andrade, } \\
\text { Victor Brecheret, Adoniran } \\
\text { Barbosa (músico) }\end{array}$ & $\begin{array}{r}\text { Charoux, Enrico Vio, Aladino Divani, } \\
\text { Alfredo Norfini, Domiziano Rossi, } \\
\text { Felizberto Ranzini, Almeida Júnior, } \\
\text { Pedro Alexandrino, Waldemar da } \\
\text { Costa }\end{array}$ \\
\hline \begin{tabular}{|l|} 
Academia de \\
Belas Artes de \\
Budapeste
\end{tabular} & 1908 & $\begin{array}{r}\mathrm{em} \\
\text { funciona } \\
\text { mento; } \\
\text { atualment } \\
\mathrm{e} \\
\text { Universid } \\
\text { ade } \\
\text { Húngara } \\
\text { de Artes }\end{array}$ & Féjer & & \\
\hline $\begin{array}{l}\text { Instituto } \\
\text { Profissional } \\
\text { Masculino }\end{array}$ & $\begin{array}{r}\text { 1911, como } \\
\text { Escola } \\
\text { Profissional } \\
\text { Masculina }\end{array}$ & $\begin{array}{r}\mathrm{em} \\
\text { funciona } \\
\text { mento } \\
\text { (reformul } \\
\text { ado) }\end{array}$ & Sacilotto & $\begin{array}{r}\text { Marcelo Grassmann, Otávio } \\
\text { Araújo }\end{array}$ & \\
\hline \begin{tabular}{|l|} 
Escola de \\
Belas Artes de \\
Araquara
\end{tabular} & c. 1930 & 1969 & Lauand & $\begin{array}{r}\text { Francisco Amêndola, Sidney } \\
\text { Rodrigues, Ernesto Lia }\end{array}$ & $\begin{array}{r}\text { Quirino Campofiorito, Hilda } \\
\text { Campofiorito, Mario Ybarra de } \\
\text { Almeida, Francisco Amêndola, } \\
\text { Domenico Lazzarini }\end{array}$ \\
\hline \begin{tabular}{|l|} 
Ateliê de \\
Samson Flexor \\
(antes do \\
Atelier- \\
Abstração) \\
\end{tabular} & $\begin{array}{r}\text { entre } 1948 \text { e } \\
1951\end{array}$ & 1951 & Maluf & & Samson Flexor \\
\hline $\begin{array}{l}\text { Escola Livre } \\
\text { de Artes } \\
\text { Plásticas }\end{array}$ & 1949 & 1949 & Maluf & $\begin{array}{l}\text { Aldemir Martins, Mário } \\
\text { Gruber, Marcelo Grassmann }\end{array}$ & $\begin{array}{r}\text { Poty, Flávio Motta, Alfredo Volpi, } \\
\text { Aldo Bonadei, Danilo di Prete, Victor } \\
\text { Brecheret }\end{array}$ \\
\hline \begin{tabular}{|l|} 
Instituto de \\
Arte \\
Contemporân \\
ea (IAC) \\
\end{tabular} & 1951 & 1953 & $\begin{array}{r}\text { Maluf, Barros, } \\
\text { Nogueira Lima, } \\
\text { Wollner, Haar } \\
\text { (professor) } \\
\end{array}$ & $\begin{array}{r}\text { Emilie Chamie (designer), } \\
\text { Ludovico Martino (designer), } \\
\text { Flávio Phebo }\end{array}$ & $\begin{array}{r}\text { Haar, Roger Bastide, Jacob Ruchti, } \\
\text { Pietro Maria Bardi, Lina Bo Bardi, } \\
\text { Oswaldo Bratke, Roberto Sambonet, } \\
\text { Flávio Motta }\end{array}$ \\
\hline Escola de Ulm & 1953 & 1968 & Barros, Wollner & $\begin{array}{r}\text { Mary Vieira, Almir Mavignier, } \\
\text { Rolf Müller (designer), Bernd } \\
\text { Meurer } \\
\text { (designer), Max Graf } \\
\text { (arquiteto) }\end{array}$ & $\begin{array}{r}\text { Rodolfo Bonetto, Josef Albers, Frei } \\
\text { Otto, Karl Gerstner, Etienne } \\
\text { Grandjean, Ralf Dahrendorf, Hans } \\
\text { Magnus Enzensberger, Walter Gropius, } \\
\text { Mies van der Rohe, Johannes Iten }\end{array}$ \\
\hline
\end{tabular}

Tabela I. Quadro sintético sobre as instituições de formação artística frequentadas pelos concretos paulistas entre as décadas de 1930 e 1950 nas cidades de São Paulo, Roma, Cracóvia, Araquara e Budapeste.

R. Inter. Interdisc. Art\&Sensorium, Curitiba, v.8, n.1, p. 138 - 152 Jan.- Jun. 2021 
Adicionalmente, são comentados os estudos universitários fora da área de artes de alguns dos artistas analisados. Assim, são discutidas as principais instituições de ensino do período com as quais os concretistas se relacionaram formalmente, fosse como alunos, fosse como professores.

O Liceu de Artes e Ofícios e o Instituto Profissional Masculino eram escolas profissionalizantes da cidade de São Paulo. Esse tipo de escola foi bastante importante na primeira metade do século XX: ofereciam disciplinas básicas e outras específicas para formar profissionais para a indústria e o comércio locais, arregimentando alunos nas classes baixa e média baixa. Formava marceneiros, tipógrafos, operários, contadores, entre outros. Ainda que não fossem escolas de artes, contribuíram para que os concretistas aqui estudados aprendessem ofícios, socializassem, inclusive com outros que se tornariam artistas também, e aprendessem certas técnicas úteis na lide artística.

No Liceu, estudaram Fiaminghi e Charoux (AMARAL, 1982, p.68). Ali, Charoux foi iniciado pelo professor Waldemar da Costa na técnica da pintura e, mesmo sem ainda ter finalizado o curso foi convidado a se tornar professor da instituição, dado seu destaque como aluno (SPINELLI, 2020, p. 6). Charoux começou a lecionar nessa instituição em 1948, quando "[...] aproxima-se do grupo de artistas interessados na poética construtivista [...]", isto é, os que passarão a praticar abstracionismo geométrico mais tarde (INSTITUTO DE ARTE CONTEMPORÂNEA, 2017, s.p.). Foi nessa instituição que Charoux aprendeu a trabalhar com régua, compasso, tira-linhas e transferidor (SPINELLI, 2020, p. 6), objetos que inicialmente eram importantes para sua atuação na indústria têxtil e, mais tarde, seriam fundamentais para sua prática artística concretista.

No Instituto, estudou Sacilotto. Outros que ali estudaram e se tornaram artistas posteriormente foram Marcello Grassmann, Otávio Araújo, Alfredo Volpi e Francisco Rebolo. Exemplos de disciplinas ministradas ali são: entalhe, gravura, mecânica, fundição e letrismo. Nessa instituição, Sacilotto fez disciplinas de mecânica e entalhe, tendo se diplomado em pintura e decoração. Peculiarmente, a matrícula de Sacilotto, ainda menino, nessa escola envolveu um engano. Tendo um amigo do pai do menino notado talento artístico em seus desenhos, indicou que se matriculasse o garoto em uma escola de artes. Para o avô, que realizou a matrícula, a oferta de aulas de pintura (aqui, de paredes) e de marcenaria configuraria uma escola de artes. (MEMÓRIA..., 2011a). Nessa instituição, aprofundou contato com professor de grande sensibilidade artística, o qual o orientou. (MEMÓRIA..., 2011b). Sacilotto afirmou que ele e seus colegas do Grupo Ruptura possuíam artesanato para produzir trabalhos artísticos e, como justificativa, arrolou seus estudos no Instituto e o "[...] grupo Ruptura, onde, ao lado do estudo teórico, nos damos a toda sorte de experimentos técnicos, inclusive com matérias novas, como a pintura a duco, o nordex, o esmalte, etc.", em suas palavras (BANDEIRA, 2002, p.53).

A importância dessas duas instituições para o concretismo paulista se deu mais pela socialização entre os que se tornariam concretistas e pelo contato inicial com técnicas artísticas em um sentido amplo do que por terem possibilitado um mergulho dos artistas em formação no mundo das artes. A seguir, abordam-se instituições formativas propriamente do campo artístico.

A Escola Livre de Arte Plásticas foi fundada por Poty e Flávio Motta possivelmente em 1949 e teve curta existência, encerrando suas atividades provavelmente nesse mesmo ano. Entre seus professores, estavam Alfredo Volpi, Aldo Bonadei, Danilo Di Prete e Victor Brecheret. Entre seus alunos, esteve Maluf. (O ARTISTA, 2017). Patrocinada pelo MAM-SP, a Escola tinha "por objetivo orientar as vocações artísticas num ambiente de trabalho e de intimidade com os meios materiais de expressão" (ESCOLA..., 1949). De acordo com Costa (2017, p.61-62), "pode-se notar que a Escola Livre antecipa um programa de cursos que seria em seguida desenvolvido nos museus [...]". Maluf, contrastando a frequência da Escola com a de outros dois ateliês, relatou ter se identificado com ela, dadas suas propostas artísticas mais novas, tendo concluído que "é isso o que quero" (BANDEIRA, 2002, p.41). Talvez a principal importância da Escola Livre de Artes Plásticas tenha sido esse caráter de descoberta de uma arte diferente da então dominante, além de ser um espaço para seu desenvolvimento, ainda que de curtíssima duração.

Outra instituição frequentada por Maluf durante curto período foi o ateliê de Samson Flexor, antes que este criasse o Atelier-Abstração, que, criado em 1951, duraria até fins dessa década e ainda teria uma outra edição (MAGALHÃES, 2016, p.9). Maluf possivelmente frequentou o ateliê de Flexor em 1950 ou 1951 e lá produzia óleos figurativos. Uma vez que suas pesquisas estéticas já tomavam o rumo de uma abstração geométrica mais rigorosa, Maluf significativamente não passou a participar do novo ateliê de Flexor, que abarcava pesquisas geometrizantes, muitas vezes cubistizantes.

Abordam-se agora duas instituições de ensino que se destacam das duas anteriores, pois tinham um perfil mais atualizado, abrangente e moderno. Isto é, estavam preocupadas em trabalhar com diversas linguagens artísticas,

R. Inter. Interdisc. Art\&Sensorium, Curitiba, v.8, n.1, p. 138 - 152 Jan.- Jun. 2021 
mas não apenas — atividades do mundo prático também eram ali abordadas em pé de igualdade. As instituições são o Instituto de Arte Contemporânea e a Escola de Ulm.

O Instituto de Arte Contemporânea (IAC) do Masp foi um dos tripés da atividade do nascente museu ao ser uma escola de design e artes. Inaugurado em 1951, inspirado em Bauhaus e no Institute of Design de Chicago, durou até 1953. Teve como alunos: Maluf, Geraldo, Nogueira Lima e Wollner; como professor, Haar. Segundo Leon (2012, p.83), o diretor do museu e do IAC, Pietro Maria Bardi “[...] se alinhava entre os modernos que, no período pós-guerra, entendiam o lugar privilegiado do design na vida cotidiana e lhe delegava lugar tão nobre quanto o da pintura e o da escultura", o que explicaria a criação do IAC. O Instituto teve como coordenadora Lina Bo Bardi e tinha como intuito formar profissionais para atuar na nascente indústria local. A escola formou trinta alunos, alguns dos quais se tornariam os primeiros designers brasileiros: Emilie Chamie, Ludovico Martino, Estella Aronis e os concretistas Nogueira Lima e Wollner. Ali ministraram aulas artistas, arquitetos e um sociólogo, Roger Bastide. Na opinião de Wollner (1998, p.232), "as posturas inovadoras do IAC, centradas principalmente nas informações de Lina Bo Bardi e Jacob Ruchti [professor da instituição] precederam, inclusive, as intenções do movimento concreto, mais tarde exposto pelo Manifesto Ruptura." Maluf, também ex-aluno, cursou no IAC apenas um semestre (o curso durava dois) e ofereceu relato que indica o impacto que essa escola teve sobre o concretismo paulista:

[...] Os professores do IAC fizeram uma limpeza radical: ensinaram-nos que não se tinha de defender nenhuma tradição, porque no Brasil não havia tradição de artes plásticas. Nós começávamos a história; começávamos um processo artístico totalmente inusitado, a Arte Concreta. (BANDEIRA, 2002, p.41).

O IAC pode ser compreendido como uma exceção no rol de instituições de ensino formal das artes aqui estudado, na medida em que oferecia formação abrangente e atualizada para seus alunos. Talvez por ser exceção, sucumbiu apenas dois anos após ter aberto. Leon (2014, s.p.) pontuou que, "na São Paulo do IV Centenário, que se metropolizava, o desenho industrial autônomo - e uma escola para produzi-lo - ainda não tinha lugar."

Outra exceção a ser considerada é uma escola que foi referência para os concretistas brasileiros, a Escola Superior da Forma, localizada em Ulm, na Alemanha, comumente chamada de Escola de Ulm. Fundada por Max Bill, pretendeu-se que essa escola de design desse continuidade aos ideais de Bauhaus. Seus alunos tinham aulas teóricas e eram incentivados a fazer muitas atividades práticas. Entre os concretistas de São Paulo, dois estudaram lá: Barros, que lá estudou por apenas um ano, e Wollner, que completou o curso dessa escola e que se tornou um designer pioneiro no Brasil. Pignatari apenas a visitou. A importância dessa escola para os concretistas se dá principalmente no plano das ideias dos concretistas relacionadas à produção artística porque ela articulava e integrava artes e indústria, o que era almejado por esses vanguardistas.

Além dessa escola na Alemanha, é importante discutir outras instituições em outros locais, dada a origem variada dos concretistas. Lauand, por exemplo, se formou no interior de São Paulo. Já Cordeiro estudou em Roma, Itália, Féjer, na Hungria e Haar, na Polônia.

Lauand mudou cedo com sua família de sua natal Pontal para Araraquara, ambas no interior de São Paulo. Lá concluiu os estudos na Escola de Belas Artes de Araraquara e também se formou professora escolar. Foi lhe oferecida a chance de estudar na Itália, o que foi impedido por seu pai. A artista conheceu os concretistas após mudar-se para a capital, especificamente na II Bienal, evento em que foi monitora. Considerando-se o perfil da Escola de Belas Artes de Araraquara e suas relações com a Escola Nacional de Belas Artes e outras academias, pode-se afirmar que ela tinha perfil acadêmico. Inaugurada aproximadamente em 1930, a academia abriu-se para tendências modernistas apenas nos anos 1950. Certamente, essa instituição forneceu formação técnica avançada para Lauand, ainda que dentro dos parâmetros acadêmicos, que eram bastante diversos dos que a artista desenvolveria sua obra nas décadas seguintes.

Certas instituições de ensino artístico europeias devem ser abordadas dado que alguns dos concretistas migraram para o Brasil já artistas formados. Cordeiro era filho de italiano e brasileira, tendo nascido em Roma e sido registrado como brasileiro. Migrou para o Brasil já artista formado. Na Itália, estudou no secundário Liceu Tasso e na Academia de Belas Artes de Roma. Féjer se formou na Academia de Belas Artes de Budapeste, onde teve aulas de história da arte e estética e de prática de composição (SPINELLI, 2020, p. 4). Haar estudou arte aplicada à indústria na Academia de Belas Artes de Cracóvia. As três academias são hoje centenárias e estavam alinhadas ao ensino acadêmico, com características como se basear em cópias de mestres e valorizar certos gêneros artísticos (histórico, por exemplo). Dessa maneira, pode-se dizer que contribuíram com formação rigorosa em termos técnicos para os futuros concretistas, que tiveram de fazer posteriormente suas explorações estéticas contrariando

R. Inter. Interdisc. Art\&Sensorium, Curitiba, v.8, n.1, p. 138 - 152 Jan.- Jun. 2021 
essa formação, uma vez que passaram a trabalhar com poéticas e materiais inusitados para o sistema acadêmico. É lícito supor que os estudos nessas academias foram cruciais para os desenvolvimentos teóricos implicados no Manifesto Ruptura.

De modo suplementar, apresentam-se as instituições universitárias frequentadas pelos sete dos concretistas paulistas que tiveram estudos de nível superior — isto é, formação formal — fora do campo das artes. ${ }^{7}$ Os três poetas concretistas cursaram Direito na USP. Posteriormente, Haroldo e Pignatari fizeram doutorado em Letras. Nogueira Lima também realizou doutorado, tendo antes se graduado em Arquitetura na Universidade Presbiteriana Mackenzie. Nessa mesma instituição, Wladyslaw se formou em Engenharia. Maluf se formou em Administração de Empresas na Fundação Getúlio Vargas. Féjer se formou em Engenharia Química na Hungria.

Uma vez que essas áreas de estudo são bastante distintas da área de Artes, é difícil afirmar o impacto direto que esses estudos tiveram sobre o desenvolvimento do concretismo. De toda forma, pode-se considerar que essa instrução contribuiu para, por exemplo, uma abertura de questões teóricas, o que se relaciona com certos aspectos teóricos do concretismo. Sobre a graduação de Féjer, é possível afirmar mais concretamente que ela lhe proveu não só conhecimentos para sua atuação como químico industrial como também materiais, em especial tintas, que foram utilizados pelos concretistas.

\section{Formação artística não formal dos artistas concretos}

Aqui se abordam e se discutem alguns dos ambientes ou eventos que contribuíram para a formação não formal dos artistas concretistas na São Paulo dos anos 1950, sem pretensão de esgotar o tópico. São eles a Seção de Arte da Biblioteca Municipal, o Masp, o MAM-SP, as bienais de arte e os redutos boêmios. Também é discutida a repercussão da atuação profissional na produção artística dos concretistas. Essas instituições são apresentadas na Tabela II:

\begin{tabular}{|c|c|c|c|c|c|}
\hline Instituição & $\begin{array}{r}\text { Ano de } \\
\text { fundaç } \\
\text { ão }\end{array}$ & Ano de encerramento & $\begin{array}{r}\text { Artistas concretos que } \\
\text { frequentaram }\end{array}$ & $\begin{array}{r}\text { Outros artistas que } \\
\text { frequentaram }\end{array}$ & $\begin{array}{r}\text { Proprietários/fu } \\
\text { ndadores/dirige } \\
\text { ntes }\end{array}$ \\
\hline $\begin{array}{l}\text { Cantina Treze } \\
\text { de Maio }\end{array}$ & $\begin{array}{r}\text { déc. } \\
1940 ?\end{array}$ & $\begin{array}{r}\text { 1952, quando se } \\
\text { transformou na cantina } \\
\text { Il Cacciatore }\end{array}$ & $\begin{array}{r}\text { Nogueira Lima, Cordeiro, } \\
\text { Augusto, Pignatari }\end{array}$ & $\begin{array}{r}\text { Mário Schenberg (crítico), } \\
\text { Alfredo Volpi }\end{array}$ & Luiz Vespero \\
\hline $\begin{array}{l}\text { Seção de Arte } \\
\text { da Biblioteca } \\
\text { Municipal }\end{array}$ & 1945 & $\begin{array}{r}\text { em funcionamento, sob } \\
\text { outro nome }\end{array}$ & virtualmente, todos os 15 & $\begin{array}{r}\text { Cláudio Willer (poeta), Maria } \\
\text { Bonomi, Mário Chamie } \\
\text { (poeta), José Arthur Giannotti } \\
\text { (filósofo), Marcello Grassmann }\end{array}$ & $\begin{array}{r}\text { Maria Eugênia } \\
\text { Franco, Sérgio } \\
\text { Milliet }\end{array}$ \\
\hline $\begin{array}{l}\text { Clubinho dos } \\
\text { Artistas }\end{array}$ & 1945 & final da déc. 1950 & $\begin{array}{r}\text { Sacilotto, Fiaminghi, Lauand, } \\
\text { Cordeiro }\end{array}$ & $\begin{array}{r}\text { Francisco Rebolo, Flávio de } \\
\text { Carvalho, Yolanda Mohaly }\end{array}$ & Francisco Rebolo \\
\hline Masp & 1947 & em funcionamento & $\begin{array}{r}\text { Maluf, Barros, Nogueira } \\
\text { Lima, Wollner, Haar }\end{array}$ & $\begin{array}{r}\text { Cândido Portinari, Ernesto de } \\
\text { Fiori }\end{array}$ & $\begin{array}{r}\text { Assis } \\
\text { Chateaubriand }\end{array}$ \\
\hline $\begin{array}{l}\text { Galeria } \\
\text { Domus }\end{array}$ & 1947 & 1951 & Wladyslaw & $\begin{array}{r}\text { Alfredo Volpi, Aldo Bonadei, } \\
\text { Raphael Galvez, Emídio de } \\
\text { Souza, Lívio Abramo }\end{array}$ & $\begin{array}{r}\text { Anna Maria } \\
\text { Fiocca, Pasquale } \\
\text { Fiocca }\end{array}$ \\
\hline Bar do Museu & $1948 ?$ & $\begin{array}{r}\text { em funcionamento, em } \\
\text { outro endereço }\end{array}$ & & $\begin{array}{r}\text { Tarsila do Amaral, Di } \\
\text { Cavalcanti e Oswald de } \\
\text { Andrade }\end{array}$ & \\
\hline MAM-SP & 1948 & em funcionamento & exposição "Ruptura" (1952) & Di Cavalcanti, Anita Malfatti & $\begin{array}{r}\text { Francisco } \\
\text { Matarazzo } \\
\text { Sobrinho }\end{array}$ \\
\hline
\end{tabular}

\footnotetext{
${ }^{7}$ Esse número é maior, já que alguns outros artistas estudaram em academias de belas artes sobre as quais não há informação exata sobre o nível dos estudos. Sabe-se com certeza, por exemplo, que a Academia de Belas Artes de Roma, onde Cordeiro estudou, é hoje de nível superior. Sabe-se, também com certeza, que a Escola de Belas Artes de Araraquara, cujas atividades já foram encerradas, não apresentava nível superior. Por outro lado, é necessária pesquisa aprofundada para se saber informações específicas da academia romana e de outras academias à época que os artistas aqui estudados as frequentaram.
}

R. Inter. Interdisc. Art\&Sensorium, Curitiba, v.8, n.1, p. 138 - 152 Jan.- Jun. 2021 


\begin{tabular}{|l|r|r|r|r|r|}
\hline $\begin{array}{l}\text { Bienal de Arte } \\
\text { de São Paulo }\end{array}$ & 1951 & em andamento & virtualmente, todos os 15 & $\begin{array}{r}\text { Flávio Motta, Wolfgang } \\
\text { Pfeiffer, Tomás Maldonado, } \\
\text { Romero Brest }\end{array}$ & $\begin{array}{r}\text { Francisco } \\
\text { Matarazzo } \\
\text { Sobrinho }\end{array}$ \\
\hline
\end{tabular}

Tabela II. Quadro sintético das instituições de formação artística não formal frequentadas pelos concretos paulistas entre as décadas de 1930 e 1950 na cidade de São Paulo.

Atualmente, a Seção de Arte da Biblioteca Municipal de São Paulo é a Sala de Artes Sérgio Milliet da Biblioteca Mário de Andrade, órgão da prefeitura paulistana localizado no centro da cidade. Foi instituída em 1945 por Sérgio Milliet (1898-1966), diretor da biblioteca, o qual designou Maria Eugênia Franco (1915-2000) como sua responsável. Formou-se coleção de arte em papel, composta de obras de nomes significativos da arte ocidental e abrigada nessa sala. De acordo com Farias (2013, p.39), esse espaço foi pioneiro no Brasil, sendo "[...] a primeira instituição voltada à aquisição, conservação, estudo e apresentação de arte moderna [...]”. Assim, numa metrópole com raros museus ou espaços onde se podia ver arte, quiçá arte moderna, a Seção passou a ser frequentada por artistas e intelectuais, inclusive pelos concretistas. Herkenhoff (2017) destacou a importância de Maria Eugênia Franco, uma vez que ela assinava revistas de arte estrangeiras e avisava os artistas geométricos quando os novos números chegavam, colaborando dessa forma para o estudo e atualização deles. Crucial para o concretismo paulista, foi nesse local que se discutiu e se redigiu o Manifesto Ruptura:

Entre os frequentadores assíduos, estavam os integrantes do grupo Ruptura, Lothar Charoux, Luiz Sacilotto, Anatol Wladyslaw e Waldemar Cordeiro, que, segundo Maurício Nogueira Lima [...], redigiram seu manifesto na Seção de Arte. (BARROS, 2016, p.3).

O Masp e o MAM-SP são museus surgidos em fins da década de 1940 em São Paulo, resultados de empenho de agrupamento de pessoas diferentes. Eram localizados no mesmo edifício no centro novo da cidade. Em seus inícios, ambos se abriram para a arte moderna e apoiaram-na, uma aposta de risco à época, uma vez que era algo nascente, mesmo na Europa ou nos Estados Unidos. Note-se que, a despeito desse investimento em arte moderna, o cerne da coleção do Masp era arte europeia de movimentos ou períodos históricos anteriores. Instalados em uma cidade pobre em museus de arte, foram importantes para a modernização artística local, especialmente porque iam além de curar e montar exposições: promoviam atividades pedagógicas como aulas e palestras e mesmo exposições estavam imbuídas da preocupação de formar público.

O Masp foi inaugurado em 1947, resultado de articulações e do financiamento de Assis Chateaubriand. A essa altura, era dirigido por Pietro Maria Bardi. Além do IAC, abordado acima, e das atividades museológicas, outro importante eixo das atividades dessa instituição era a revista Habitat, que, inaugurada em 1950, foi importante canal de comunicação com a sociedade local.

O MAM-SP foi fundado em 1948, por obra de Francisco Matarazzo Sobrinho. Foi inaugurado no ano seguinte com a exposição "Do figurativismo ao abstracionismo", que expôs apenas obras abstracionistas, indicando o viés tomado pela instituição. Essa instituição oferecia cursos livres práticos de arte, fosse de gravura, fosse de desenho com modelo livre, e cursos e palestras teóricos sobre arte, entre outros; também editava publicações de arte. Foi o local onde ocorreu a mostra "Ruptura"; contudo, apenas foi cedido o espaço aos artistas, não havendo, entre outros, colaboração em recursos humanos.

A frequência pelos concretistas dessas duas instituições museológicas, em suas diversas vertentes de atividades foi, fora de toda dúvida, elemento crucial para a formação deles e para o próprio desenvolvimento do movimento artístico de vanguarda.

De acordo com Gonçalves (1978, s.p.), as cinco edições da Bienal de São Paulo, nos anos 1950, atualizavam os frequentadores em relação ao que acontecia no exterior e cumpriam papel museológico apresentando retrospectivas de movimentos modernos. Aracy Amaral (2014 [1977], p.311-312) creditou ao impacto causado pela delegação suíça na I Bienal sobre os concretistas a troca da tela pintada a óleo por Eucatex pintado com esmalte e a troca do pincel pela pistola. Wollner, em depoimento, discorreu sobre a II Bienal. De acordo com ele:

[...] a coisa mais importante que aconteceu foi a segunda Bienal neste país, abriu uma janela, a gente começou a ter contato com Calder, com Klee, Kandinsky, Malevich. De repente, tudo isso, foi um soco na cara da gente. Então o pessoal do grupo de arte concreta, principalmente, nós discutíamos muito, visitávamos a seção deles lá e ficávamos discutindo intensamente. A gente procurava pegar o Flávio Motta, que trabalhava no Museu de Arte, também o [Wolfgang] Pfeiffer [...]. Então esse pessoal orientava a gente, falava quem era, o que eles faziam, qual 
é o pensamento deles, isso para nós foi uma coisa importantíssima, porque até aquele momento você não tinha notícia daquelas pessoas [...] (HOFFMANN, 2002, p.258-259).

Wollner citou também conversas nessa ocasião com o crítico argentino Romero Brest (1905-1989), ligado à arte concreta, e Tomás Maldonado (id., ib., p.259). Também mencionou que, por ocasião dessa mostra, conversavam muito com Mário Pedrosa, no hotel no centro da capital paulista onde ficava hospedado (loc. cit.). Nota-se, assim, que essa grande exibição periódica era uma oportunidade de intenso aprendizado para esses artistas, contribuindo para lhes prover uma formação artística atualizada.

Certos redutos boêmios da cidade de São Paulo, notadamente bares e restaurantes, foram palco de reuniões de artistas concretos entre si e também com artistas de outras orientações estéticas. Maria Arminda do Nascimento Arruda (2001, p.61) descreveu os bares paulistanos de meados do século XX como "[...] espaços de vivência ampla, de estímulo aos sentidos e do cultivo ao intelecto." Cintrão e Nascimento (2002, p.12) assinalaram que a exposição "Ruptura" foi engendrada não só na mencionada Seção de Arte, como também na galeria de arte Domus, no Bar do Museu, no Clubinho dos Artistas e na cantina Treze de Maio, os quais são apresentados a seguir. Luiz Sacilotto registrou que as reuniões aconteciam desde a mostra "19 Pintores", em 1947 (SACRAMENTO, 2001, p.56). A lista de redutos boêmios não é exaustiva.

Antes de discutir os redutos boêmios, é importante abordar a galeria de arte Domus, local da primeira individual de Wladyslaw, em 1951 (o artista também participou de coletivas em 1947 e 1948) (SILVA, 2017). A Domus teve breve existência, de 1947 a 1951, e foi pioneira na comercialização exclusiva de arte moderna na capital paulista. Antes de seu surgimento e de outras do mesmo nicho, as exposições e a comercialização de arte moderna aconteciam em lugares como, entre outros, antiquários e hall de hotéis. Em um diminuto espaço de sessenta metros quadrados, realizava exposições frequentes. Segundo Bueno (1990, p.230-231), o espaço atraiu europeus imigrados nostálgicos da riqueza cultural europeia e "[...] foi se transformando em ponto de encontro de músicos, artistas plásticos, literatos e críticos de arte.” Localizado numa cidade desprovida de um mercado de arte moderna consolidado, o espaço não perdurou.

Bar do Museu é o apelido da Associação dos Amigos do Museu de Arte Moderna de São Paulo, que surgiu quando da fundação desse museu. O bar, dono de coleção de óleos e desenhos doados pelos frequentadores, era localizado no mesmo prédio do MAM-SP, acompanhando-o em sua mudança para o Parque Ibirapuera em 1958. No centro, nos seus anos iniciais, atraía um público de intelectuais e artistas, residentes ou não em São Paulo. Entre eles, estiveram Tarsila do Amaral, Di Cavalcanti e Oswald de Andrade. Retornou ao centro anos mais tarde. Ainda existe, em outro local, com outro público.

Clubinho dos Artistas era o apelido do Clube dos Artistas e Amigos da Arte, criado por Francisco Rebolo (19021980) com muitos outros artistas em 1945 (QUINTELLA; MAROVATTO, [2020]). Em sua história, arquitetos, intelectuais e artistas participam da sua direção. Constantemente lutando para conseguir dinheiro, foi espaço que, além de ser bar, hospedou palestras, debates, festas, bailes e exposições - inclusive, uma memorável briga, em 1951. Inicialmente, instalou-se em parte da Livraria Roxy, nos fundos da Galeria Itapetininga, em 1948. No ano seguinte, mudou-se para a nova sede do Instituto dos Arquitetos do Brasil. Apesar das mudanças de sede, ficava sempre no centro novo da cidade. Sacilotto conheceu Fiaminghi em 1955, quando o convidou a passar a visitar o recinto. Cabral e Rezende (1998, p.53) assentaram que

Lá iam sempre Waldemar Cordeiro, Judith Lauand, Rebolo, Flávio de Carvalho, Yolanda Mohaly, entre outros. Volpi também aparecia. Eram reuniões diárias. Bebiam litros e litros de vinho. Começava no Clubinho, acabava na Cantina Treze de Maio.

$\mathrm{Na}$ opinião de Fiaminghi, o lugar "abriu a cabeça de quem vinha do meio da publicidade [caso dele]. Foi a Universidade da Arte" (id., ib., p.55). Quintella e Marovatto ([2020], p.18) sublinharam os seguintes aspectos do Clubinho:

O Clube dos Artistas e Amigos da Arte viveu o seu auge entre o final da década de 1940 e o estertores dos anos 1950. Neste curto período, os integrantes de diversos "modernismos", pouco a pouco envelhecendo, encontravam vozes afins e uma rede de sociabilidade comum na mutante capital paulista. Para aqueles tantos e diferentes sócios, a arte, além de elemento de distinção social, era um código partilhado coletivamente, que orientava noites de divertimento, não sem espaço para sérias discussões sobre os rumos da cultura, da política e do país. Daquelas conversas saíram músicas, murais pintados, bailes, viagens, museus e acirrados debates intelectuais. Boêmio, contraditório, afetivo, múltiplo, o Clubinho se configura como um dos importantes bastidores da história da modernidade no Brasil [...].

R. Inter. Interdisc. Art\&Sensorium, Curitiba, v.8, n.1, p. 138 - 152 Jan.- Jun. 2021 
A cantina Treze de Maio se localizava no tradicional bairro italiano Bixiga, até hoje reduto da gastronomia italiana na cidade de São Paulo. Em relato sobre a boêmia década de 1950, Lima (1995, p.41) relatou que:

Naquela época, éramos jovens e gostávamos de beber bastante, pois assim nossos conceitos se soltavam melhor e o [Mário] Schenberg sempre acompanhava as nossas "noitadas". Geralmente o artista é muito boêmio. Eu, o Cordeiro, o Augusto de Campos, o Décio Pignatari e o Volpi (que, às vezes, era curiosíssimo porque não falava nada, apenas: "Eh, Eh". [...]). Nos reunimos na cantina Treze de Maio, na rua Santo Antônio, e "enchíamos a cara" violentamente. Depois de umas quatro bagaceiras, umas três garrafas de vinho, sem falar dos charutos do Mário, todo mundo ficava altamente alegre. Muitas vezes, no fim das nossas discussões, saíam brigas terríveis, principalmente porque a pessoa que liderava o nosso grupo, o Waldemar Cordeiro, era uma pessoa irascível e nervosa, além de ter grandes choques com o Schenberg por problemas artísticos e políticos. Depois saíamos abraçados e tudo ficava bem.

Por fim, cabe discutir sobre o impacto que a formação e a atuação profissional em outras áreas dos artistas tiveram em suas produções artísticas. Para alguns, o contato com técnicas e tecnologias em suas profissões repercutia em suas atuações artísticas. Exemplo é Adolpho Leirner, que afirmou haver ressonância do emprego em outras funções na produção artística e citou Sacilotto para exemplificar a influência das esquadrias metálicas em sua obra (SANDES, 2017, p.315). Nesse mesmo sentido, Fabris (2002, p.50) questionou se a "prática profissional extraartística" não teria servido de "passagem para uma nova concepção artística". Por exemplo, sobre Nogueira Lima, Politano (2018, p.393) afirmou que, entre outros fatores, é possível notar a "bancada de trabalho do arquiteto" em sua pincelada e em seu traço. De todo modo, é importante ponderar que os indivíduos têm múltiplas formas de pensar e agir no mundo circundante. Assim, talvez seja inadequado comparar a atuação de um artista e de um técnico em um mesmo indivíduo. Por outro lado, os indivíduos não são estanque, de modo que, consciente ou inconscientemente, podem transferir ideias, noções e práticas de uma frente de suas vidas para outra. Pode-se dizer que as condições objetivas do campo da arte bourdieusiano foram combinadas pelos artistas concretistas com suas trajetórias pessoais, de forma que foram transferidas ideias, noções e práticas de uma frente de suas vidas para outra, levando à produção da inovação na arte, o que dá ensejo a discussões sobre a produção artística e sobre o sujeito.

\section{Considerações finais}

Ao que tudo indica, para os artistas concretistas, a formação artística não formal superou em importância e peso a formal. Além de o sistema formal de educação artística àquela época ser incipiente no Brasil, deve-se considerar a classe social desses artistas, o que lhes restringia acesso a instituições. Quanto às instituições de ensino artístico, ressalva deve ser feita às bem estabelecidas, tradicionais e centenárias academias de belas artes europeias, onde alguns dos artistas se formaram. As academias de belas artes brasileiras não figuraram, pois os artistas que se tornariam concretistas não faziam parte de classes sociais cujos membros eram arregimentados por essas instituições. Olhando-se para os ateliês e escolas, pode-se notar que o ensino ali provido era importante para inserir seus alunos no métier artístico, porém não era capaz de prover um ensino inovador e arrojado. Quanto às academias europeias, não se pode dizer que fossem inovadoras, porém, imbuíam seus alunos de sólidas ferramentas e base teórica.

A inovação e o arrojo vistos nas ideias e práticas concretistas foi possivelmente mais um resultado da formação não formal desses artistas na São Paulo dos anos 1950. É provável que isso tenha ocorrido em função da falta de consistência do campo artístico de então, ou seja, um campo que ainda não havia se constituído inteiramente e, assim, não contava com uma autoritas centralizada, que interferiria inclusive na formação dos artistas brasileiros. Esse cenário presumivelmente colaborou para que os concretistas tivessem as liberdades artística e intelectual que beneficiariam a inovação e o arrojo do movimento concretista.

A vida boêmia tem tido papel importante para os movimentos artísticos brasileiros ao longo de, pelo menos, o último século, seja para a sociabilidade, seja para o desenvolvimento intelectual e artístico dos artistas. Porém, nem sempre é enfatizada ou discutida pela literatura relativa (exceção talvez seja o modernismo de 1922). Considerando o caso do concretismo, é possível que aqui ela tenha tido uma relevância ainda maior, dada a pouca uniformidade na educação formal obtida pelos concretistas - além, de novo, de seu caráter pouco inovador.

A Seção de Arte da Biblioteca Municipal, o Masp, o MAM-SP, as bienais de arte e os redutos boêmios foram os principais locais e momentos da formação não formal dos artistas visuais e poetas concretistas. Espaços de aprendizado coletivo, conversa, discussão e convívio, muitas vezes com pessoas com ideias novas ou diferentes,

R. Inter. Interdisc. Art\&Sensorium, Curitiba, v.8, n.1, p. 138 - 152 Jan.- Jun. 2021 
são fundamentais para a formação de um artista. Os exemplos concretos discutidos favoreceram a abertura de ideias necessária para o surgimento e estabelecimento dos artistas concretistas.

Considerando a classe social e a origem estrangeira da maioria dos concretistas, é compreensível que para eles uma sociabilidade mais livre como a da boêmia se tornasse fundamental para iniciar e solidificar laços sociais e prover aprendizado sobre artes. Eles tinham pouca inserção em ensino formal artístico, no Brasil e no exterior (os que estudaram em academias europeias, como Charoux e Cordeiro, fizeram-no antes de imigrar para o Brasil). Desse modo, não possuindo muito capital (financeiro, social ou cultural), tiveram que recorrer a esses espaços mais livres para articular o movimento. A bem da verdade, tendo-se em vista o meio cultural local em meados do século, não havia instituições sólidas que pudessem municiar, habilitar ou instrumentalizar esse ou qualquer outro movimento artístico novo e instituições inovadoras recém-criadas, como o IAC, não permaneciam.

O método da biografia coletiva mostrou-se ferramenta útil na medida em que possibilita desvendar as clivagens entre os artistas no geral e mesmo dentro do grupo dos concretistas. Por meio dela, pôde-se notar os subgrupos existentes.

Novas pesquisas podem explorar mais a fundo os estudos dos concretistas nas instituições europeias, sobre as quais pouco está disponível. Esse caminho pode ser valioso para a compreensão da origem de inovações artísticas das vanguardas abstratas do século XX no Brasil. Além disso, seria importante melhor explorar, por meio de pesquisas bibliográficas ou in loco ou ainda entrevistas com artistas e indivíduos relacionados ainda vivos, os locais de formação não formal da capital paulista. Isso possivelmente trará novos dados que auxiliarão no entendimento das dinâmicas do movimento concretista e das artes no geral em meados do século.

\section{Referências}

ALAMBERT, Francisco; CANHÊTE, Polyana. As bienais de São Paulo: da era do Museu à era dos curadores (1951-2001). São Paulo: Boitempo, 2004.

AMARAL, Aracy. O desenho jovem dos anos 40. In: Artigos e ensaios (1961-1981) São Paulo: Nobel, 1982. Arte e meio artístico: entre a feijoada e o x-burguer.

. Surgimento da abstração geométrica no Brasil. In: (Org.). Arte construtiva no Brasil: Coleção Adolpho Leirner. São Paulo: DBA Artes Gráficas, 1998.

Duas linhas de contribuição: concretos em São Paulo/neoconcretos no Rio. In: (Coord.). Projeto construtivo brasileiro na arte: 1950-1962. Rio de Janeiro: MAM; São Paulo: Pinacoteca do Estado, 2014 [1977], p.312-317.

ARRUDA, Maria Arminda do Nascimento. Metrópole e cultura: São Paulo no meio do século XX. São Paulo: Edusc, 2001.

BANDEIRA, João (Org.). Arte concreta paulista: documentos. São Paulo: Cosac Naify, 2002.

BARROS, Stella Teixeira de. Aventura e trabalho do homem-ponte: da Secção de Arte de Sérgio Milliet ao acervo contemporâneo. In: CENTRO CULTURAL SÃO PAULO. Catálogo parcial da Coleção de Arte da Cidade. São Paulo: Centro Cultural São Paulo, 2016, p.1-6.

BUENO, Maria Lúcia. Artes plásticas no Brasil: modernidade, campo artístico e mercado (de 1917 a 1964). 1990. Dissertação (Mestrado em Ciências Sociais) - Programa de Pós-Graduação em Ciências Sociais, Pontifícia Universidade Católica de São Paulo, São Paulo.

CABRAL, Isabella; REZENDE, M. A. Amaral. Hermelindo Fiaminghi. São Paulo: Edusp, 1998.

CAMPOS, Haroldo de. Construtivismo no Brasil: concretismo e neoconcretismo. In: FERREIRA, Glória (Org.). Crítica de arte no Brasil: temáticas contemporâneas. Rio de Janeiro: Funarte, 2006, p.115-126.

CHARLE, Christophe. A prosopografia ou biografia coletiva: balanço e perspectivas. In: HEINZ, Flávio Madureira (Org.). Por outra história das elites. Rio de Janeiro: FGV, 2006, p.41-54.

CINTRÃO, Rejane; NASCIMENTO, Ana Paula. Grupo Ruptura. São Paulo: Cosac \& Naify, 2002.

CORDEIRO, Waldemar. Ruptura. Correio Paulistano. São Paulo, 11 jan. 1953. Disponível em: $<$ https://icaadocs.mfah.org/s/en/item/1085337>. Acesso em: 4 maio 2020. 
COSTA, Juliana Braga. História, arte e arquitetura: Flávio Motta e o ensino como ofício. Tese (Doutorado em Arquitetura e Urbanismo) - Programa de Pós-Graduação em Arquitetura e Urbanismo, Universidade de São Paulo, São Paulo.

DURAND, José Carlos. Arte, privilégio e distinção. São Paulo: Perspectiva, 2009.

ESCOLA Livre de Artes Plásticas. O Estado de S. Paulo. São Paulo, 24 maio 1949.

FABRIS, Annateresa. Figuras do moderno (possível). In: SCHWARTZ, Jorge (Org.). Da Antropofagia a Brasília: Brasil 1920-1950. Valência: IVAM; São Paulo: FAAP; Cosac Naify, 2002, p.41-140.

GONÇALVES, Lisbeth Rebollo. As Bienais e a abstração - a década de 50. In: MUSEU LASAR SEGALL. As Bienais e a abstração: a década de 50. São Paulo: Museu Lasar Segall, 1978, s.p.

FARIAS, Agnaldo. Da Seção de Arte ao Prêmio Aquisição: a gênese do Gabinete do Desenho. arq.urb. São Paulo, n. 9, jan.-jun. 2013, p.38-43. Disponível em: < https://revistaarqurb.com.br/arqurb/article/view/354>. Acesso em: 12 maio 2020.

HEINZ, Flávio Madureira. O historiador e as elites — à guisa de introdução. In: (Org.). Por outra história das elites. Rio de Janeiro: FGV, 2006, p.7-16.

HERKENHOFF, Paulo. I. Mote geral e algumas de suas glosas, a título de introdução. In: pintura e método: projeções da década de 50. São Paulo: Instituto Tomie Ohtake, 2009, p.28-51.

. Pincelada,

Mesa 3. Arte, instituição e subjetividade: fricções - Paulo Herkenhoff (Curador Independente). Disponível em: $<$ https://www.youtube.com/watch? $\mathrm{v}=$ toI6nDUdQMo $>$. Palestra proferida em 28 set. 2012. Acesso em: 7 maio 2020 .

HOFFMANN, Ana Maria Pimenta. Entrevista com Alexandre Wollner em 18.09.2001. In: A arte brasileira na II Bienal do Museu de Arte Moderna de São Paulo: o prêmio melhor pintor e o debate em torno da abstração. 2002. Dissertação (Mestrado em História) — Instituto de Filosofia e Ciências Humanas, Universidade Estadual de Campinas, Campinas, p.255-261.

INSTITUTO DE ARTE CONTEMPORÂNEA. IAC 20 anos. São Paulo: Instituto de Arte Contemporânea, 2017.

KHOURI, Omar. Noigandres e Invenção: revistas porta-vozes da Poesia Concreta. FACOM. São Paulo, n. 16, $2^{\circ}$ sem. 2006, p.20-33.

LEON, Ethel. Escolas e museus: IAC/Masp, ESDI/MAM/IDI. In: . Design em exposição: o design no Museu de Arte Moderna do Rio de Janeiro (1968- 1978), na Federação das Indústrias de São Paulo (1978-1984) e no Museu da Casa Brasileira (1986-2002). 2012. Tese (Doutorado em História e Fundamentos da Arquitetura e do Urbanismo) - Faculdade de Arquitetura e Urbanismo, Universidade de São Paulo, São Paulo, p.82-105.

.IAC: primeira escola de design do Brasil. São Paulo: Edgard Blücher, 2014.

IAC/MASP, uma escola futurista em São Paulo. MAC-USP: 2014. Disponível em: $<$ http://www.mac.usp.br/mac/conteudo/academico/publicacoes/anais/modernidade/pdfs/ETHEL_PORT.pdf $>$.

LIMA, Maurício Nogueira. Schenberg: incentivador e crítico. In: AJZENBERG, Elza (Coord.). Mario Schenberg: arte e ciência. São Paulo: Centro Mario Schenberg de Documentação da Pesquisa em Artes, 1995, p.45-53.

MAGALHÃES, Fabio. Antônio Maluf: construções de uma equação. In: MAGALHÃES, Fabio (Org.). Antônio Maluf: construções de uma equação. São Paulo: Galeria Frente, 2016, p.8-15.

MANNHEIM, Karl. O problema das gerações. In: Sociologia do conhecimento. Porto: Rés, [1986], v. 2, p.115-174.

MEMÓRIA e Contexto: Luiz Sacilotto - $1 / 4$. Disponível em: $<$ https://www.youtube.com/watch?v=RzPx_4Z9dWI\&t=25s $>$. Publicado em: 6 jul. 2011a. Acesso em: 12 maio 2020.

MEMÓRIA e Contexto: Luiz Sacilotto - 2/4. Disponível em: $<$ https://www.youtube.com/watch?v=rnW3zH0EPE $>$. Publicado em: 6 jul. 2011b. Acesso em: 12 maio 2020.

O ARTISTA. Disponível em: <https://www.antoniomaluf.com.br/o-artista $>$. Acesso em: 12 maio 2020.

R. Inter. Interdisc. Art\&Sensorium, Curitiba, v.8, n.1, p. 138 - 152 Jan.- Jun. 2021 
PEDROSA, Mário. A Bienal de cá e pra lá. In: ARANTES, Otília (Org). Modernidade cá e lá: textos escolhidos IV. São Paulo: Edusp, 2000.

POLITANO, Stela. Maurício Nogueira Lima: o concreto inventor. In: ROSADO, Alessandra; FAZZOLARI, Cláudia; FRONER, Yacy-Ara (Orgs.). Arte concreta e vertentes construtivas: teoria, crítica e história da arte técnica (Jornada ABCA) — Comunicadores. Belo Horizonte: ABCA, 2018, p.392-394.

QUINTELLA, Pollyana; MAROVATTO, Mariano. Clube dos Artistas e Amigos da Arte. [2020]. Disponível em: $<$ https://www.centralgaleria.com/clubinho>. Acesso em: 8 maio 2020.

SACRAMENTO, Enock. Sacilotto. São Paulo: E. Sacramento, 2001.

SANDES, Luis Fernando Silva. Entrevista com o colecionador de arte Adolpho Leirner. Brasiliana: Journal for Brazilian Studies. Londres, v. 6, n. 1, Dec. 2017. Disponível em: $<$ https://tidsskrift.dk/bras/article/view/105523/154319>. Acesso em: 12 maio 2020.

. Entrevista com o artista teuto-brasileiro Almir Mavignier sobre o concretismo brasileiro. ARTis ON. Lisboa, n. 5, 2017, p.262-268. Disponível em: <http://artison.letras.ulisboa.pt/index.php/ao/article/view/150>. Acesso em: 5 maio 2020.

SILVA, José Armando Pereira. O mercado de arte moderna em São Paulo: 1947-1951. São Paulo: MAM-SP, 2017.

SPINELLI, João. J. Diálogo concreto. Kazmer Fejer e Lothar Charoux: virtualidades ópticas. Galeria Berenice Arvani: 2020.

WOLLNER, Alexandre. A emergência do design visual. In: AMARAL, Aracy (Org.). Arte construtiva no Brasil: Coleção Adolpho Leirner. São Paulo: DBA Artes Gráficas, 1998, p.223-260. 